\title{
An Investigation on Sheeting Acting as a Diaphragm on a Reinforced Precast Concrete Frame
}

\author{
Sergiu-Gheorghe Țere ${ }^{1 *}$, Bogdan Hegheș², Horea Constantinescu² \\ ${ }^{1}$ Department of Structural Mechanics, Faculty of Civil Engineering, Technical University of Cluj-Napoca, C-tin Daicoviciu Street, nr. 15, \\ 400020 Cluj-Napoca, Romania \\ ${ }^{2}$ Department of Structures, Faculty of Civil Engineering, Technical University of Cluj-Napoca, C-tin Daicoviciu Street, nr. 15, 400020 \\ Cluj-Napoca, Romania \\ * Corresponding author, e-mail: sergiu.tere@mecon.utcluj.ro
}

Received: 24 March 2020, Accepted: 15 July 2020, Published online: 27 August 2020

\begin{abstract}
It is well-known that for single-storey steel structures, the framework is greatly strengthened and stiffened following the attachment of the roof, floors and walls. The panels in the roofing, flooring and side cladding are also known as "shear diaphragms" by virtue of their resistance to being deformed into parallelograms. This has been verified by on-site practical experience of many structures and design provisions are available for structural engineers. Despite the fact that for single-storey structures, the corrugated steel sheets are the standard elements in constructing the envelopes, in what concerns the reinforced concrete frames there are no guidelines nor recommendations on how to consider the diaphragm effect in structural analysis. In order to better understand the interaction between the corrugated steel sheets and the reinforced concrete frame, a real precast reinforced concrete frame structure was built for experimental testing. The aim of the experimental test is to study the diaphragm effect for reinforced concrete structures and based on the results to identify the discrepancies identified compared to steel structures. The investigation attempts to provide a starting point for future research on the stressed skin design acting on reinforced concrete frames. At the end of the article conclusions are drawn based on the experience obtained during the experimental test.
\end{abstract}

Keywords

corrugated steel sheets, stressed skin design, precast concrete frame, shear diaphragms, diaphragm action

\section{Introduction}

Nowadays it is recognized that with proper fastening of the corrugated steel sheets to the structural elements, the framework is greatly strengthened and stiffened. Plenty of full scale tests are available and practical experience of many steel building designs confirms that by considering the cladding into static and dynamic calculations [1-8], the structural response of the building performs closer to real life behavior. The corrugated sheets behave as diaphragms by virtue of their resistance and stiffness in shear. The design specifications which takes the diaphragm effect into consideration is called "diaphragm design" [9] in the United States and "stressed skin design" in Europe [10].

The ECCS "European recommendations for the stressed skin design of steel structures" [10] is the European design guide for stressed skin design and it is intended to be applied only for steel structures. The document provides recommendations on how the influence of the diaphragm effect of the corrugated steel sheets is to be considered in static and dynamic analysis of steel structures. The document gives no guidance or instructions regarding the diaphragm effect for reinforced concrete structures although the same corrugated sheets that creates the diaphragm effect are used for cladding in both steel and concrete frames.

It has become a construction standard that the envelopes for single-storey frame structures are set up using corrugated steel sheets, regardless if the structural frame is made from steel or reinforced concrete. The reason is due to the fact that the corrugated steel sheets are well suited for creating light envelopes while covering large spans and supporting the thermal and hydro insulation.

Although corrugated steel sheets are used for the same purpose in both steel and reinforced concrete structures, no guidance or recommendations are offered for the consideration of the stressed skin action in reinforced concrete 
structures. The authors identified the lack of research in the field and the scope of the experimental test was to start a study on the sheeting acting as a diaphragm on concrete frames. The present article describes the first steps attempted in the analysis of a reinforced concrete frame laterally strengthened and stiffened with corrugated steel sheets. For a better understanding of the details that creates disparity between reinforced concrete structures and steel structures, experimental testing on a real concrete structure had to be performed.

\section{Objectives of the experimental program}

The study focused on investigating the behavior of the sheeting acting as a diaphragm on a precast reinforced concrete frame and aims to prepare the first steps for future research by identifying the main discrepancies between reinforced concrete structures and steel structures with the aim of laying a path for a future guide on sheeting acting as a diaphragm in reinforced concrete buildings.

The ECCS [10] is used as a starting point in evaluating the stressed skin acting on a reinforced concrete structure. In the article a comparison between steel and reinforced concrete frames is made by accepting that the ECCS equations (Eqs. (1) to (7) presented in Section 6 in this article) for determining the flexibility of the diaphragm can be adopted for concrete structures. By considering that the principles described in the ECCS can be used in evaluating the response of reinforced concrete structures the scope is to identify the variables that produce the most disparities for reinforced concrete structures. Identifying the difference between steel and concrete will lead to the adaptation of the ECCS equations so than it could be used for reinforced concrete structures also.

The experimental program intends to present the problems that emerge in fastening the corrugated sheets (Fig. 1) to the precast reinforced concrete structure and to determine the behavior of the corrugated steel sheets attached on both sides of the frame [11-12].

\section{Presentation of the tested frame}

A prefabricated concrete frame structure was built in the laboratory of the Technical University of Cluj-Napoca, Faculty of Civil Engineering. The frame was laterally stiffened with corrugated steel sheets. To better understand the diaphragm action created by the corrugated panels, the frame was subjected to several sequences of increased displacements controlled cycles. The steps followed in the experimental test are in accordance to the ACI T1.01 standard [13].
The geometry of the prefabricated reinforced concrete frame structure was based on a Prototype Frame. Because the envisioned Prototype Frame had relatively large dimensions it made it unsuited for lab testing but based on the theory of similarity, with a transformation factor $\lambda=3$, the dimensions of the Prototype Frame were reduced resulting the Model Frame (Fig. 2). The Model Frame is a more rational structure that can be built and manipulated in the Laboratory.

The footprint of the Model Frames is $2.80 \times 4.00 \mathrm{~m}$ and the structure total height, measured from the bottom of the foundations, reaches up to $2.98 \mathrm{~m}$. The frame has a bay of $2.00 \times 3.00 \mathrm{~m}$. The columns are made of precast reinforced concrete with a cross section of $20 \times 20 \mathrm{~cm}$. The beams are also precast reinforced concrete with $20 \times 22 \mathrm{~cm}$ cross section. After the topping was added, the actual section

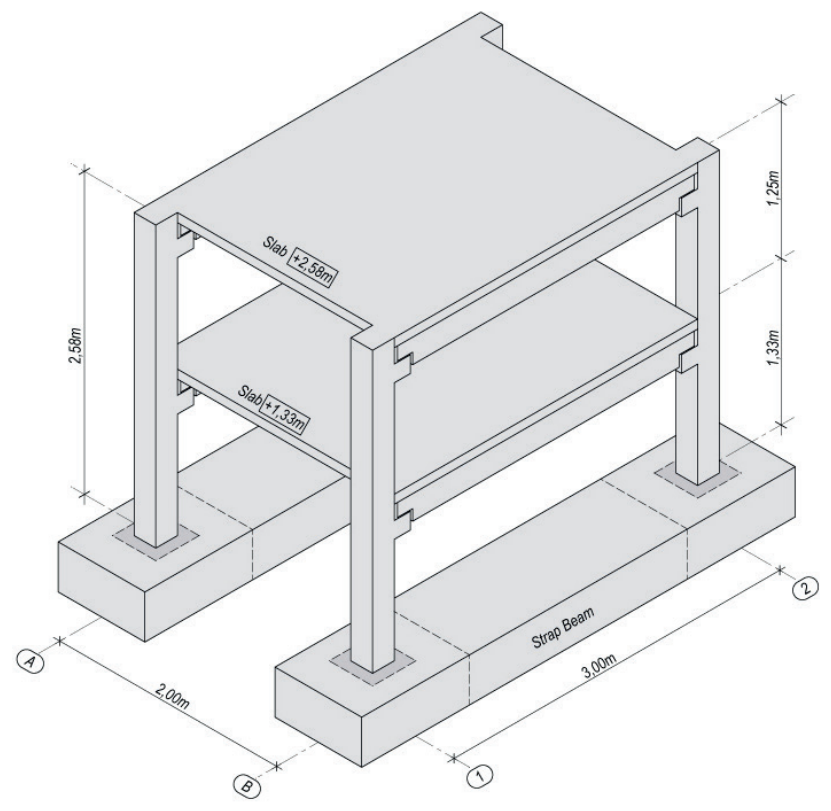

Fig. 1 Corrugated steel sheet panel section

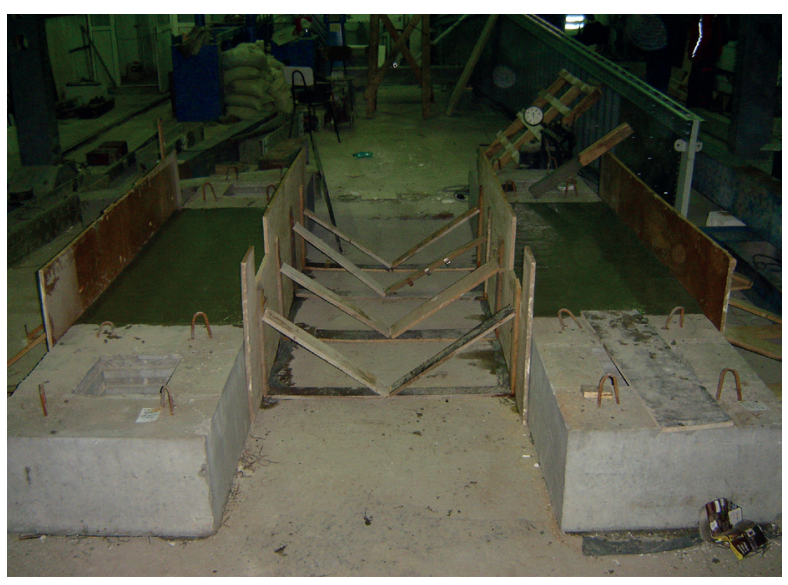

Fig. 2 3D representation of the model Frame tested in the laboratory 
of the beams is $20 \times 30 \mathrm{~cm}$. The structure has two stories with bottom story height $H_{b s}=1.33 \mathrm{~m}$ and the top story height $H_{t s}=1.25 \mathrm{~m}$. In Table 1 is presented the geometry of the Prototype Frame compared to the Model Frame that was subjected to the experimental testing.

The Model Frame was designed adopting commonly used details for precast concrete frame structures constructed in high seismic areas. The pocket foundations, columns and beams have been executed off site in a precast concrete factory. Prior to bringing the precast concrete elements in the Laboratory for setting-up the Model Frame, testing on the precast elements have been conducted to obtain the material proprieties. Table 2 presents the material proprieties and in Fig. 3 is presented the corrugated sheet cross section.

The columns were positioned in the precast pocket foundations. The space remaining between the pocket foundation and the column was cast-in-place using mortar of bedding.

The pocket precast foundations have been jointed together by a strap beam to ensure that the structure is stiffened enough to prevent any possible uplifting or slipping (Fig. 4).
Table 1 Geometry of structural elements and structure

\begin{tabular}{lcc}
\hline Structural Element & Prototype Frame & Model Frame \\
\hline Column & $60 \times 60 \mathrm{~cm}$ & $20 \times 20 \mathrm{~cm}$ \\
Beam (precast) & $60 \times 66 \mathrm{~cm}$ & $20 \times 22 \mathrm{~cm}$ \\
Beam (after topping) & $60 \times 90 \mathrm{~cm}$ & $20 \times 30 \mathrm{~cm}$ \\
Slab & $24 \mathrm{~cm}$ & $8 \mathrm{~cm}$ \\
Bottom Story Height & $4.00 \mathrm{~m}$ & $1.33 \mathrm{~m}$ \\
Top Story Height & $3.75 \mathrm{~m}$ & $1.25 \mathrm{~m}$ \\
Bay & $6.00 \times 9.00 \mathrm{~m}$ & $2.00 \times 3.00 \mathrm{~m}$ \\
\hline
\end{tabular}

Table 2 Concrete and steel material proprieties

Precast frame elements

C20/25

C30/37

$\mathrm{C} 40 / 50$

\begin{tabular}{lccc} 
& C20/25 & C30/37 & C40/50 \\
\hline S500C & Strap beam & - & $\begin{array}{c}\text { Precast Pad } \\
\text { Footings, Beams, } \\
\text { Columns }\end{array}$ \\
S355 (PC52) & - & Slab & - \\
\hline
\end{tabular}

Corrugated sheet panels

\begin{tabular}{ccc}
$f_{y}[\mathrm{MPa}]$ & $\mathrm{E}[\mathrm{MPa}]$ & Weight $\left[\mathrm{kN} / \mathrm{mm}^{2}\right]$ \\
\hline 270 & 205000 & 0.038 \\
\hline
\end{tabular}

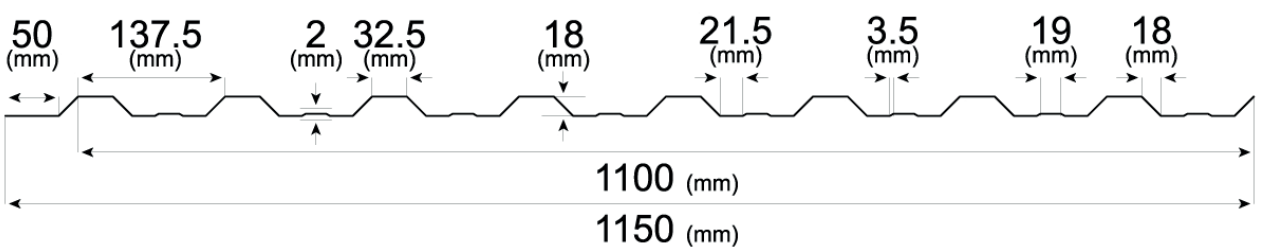

Fig. 3 Model Frame in the testing stand

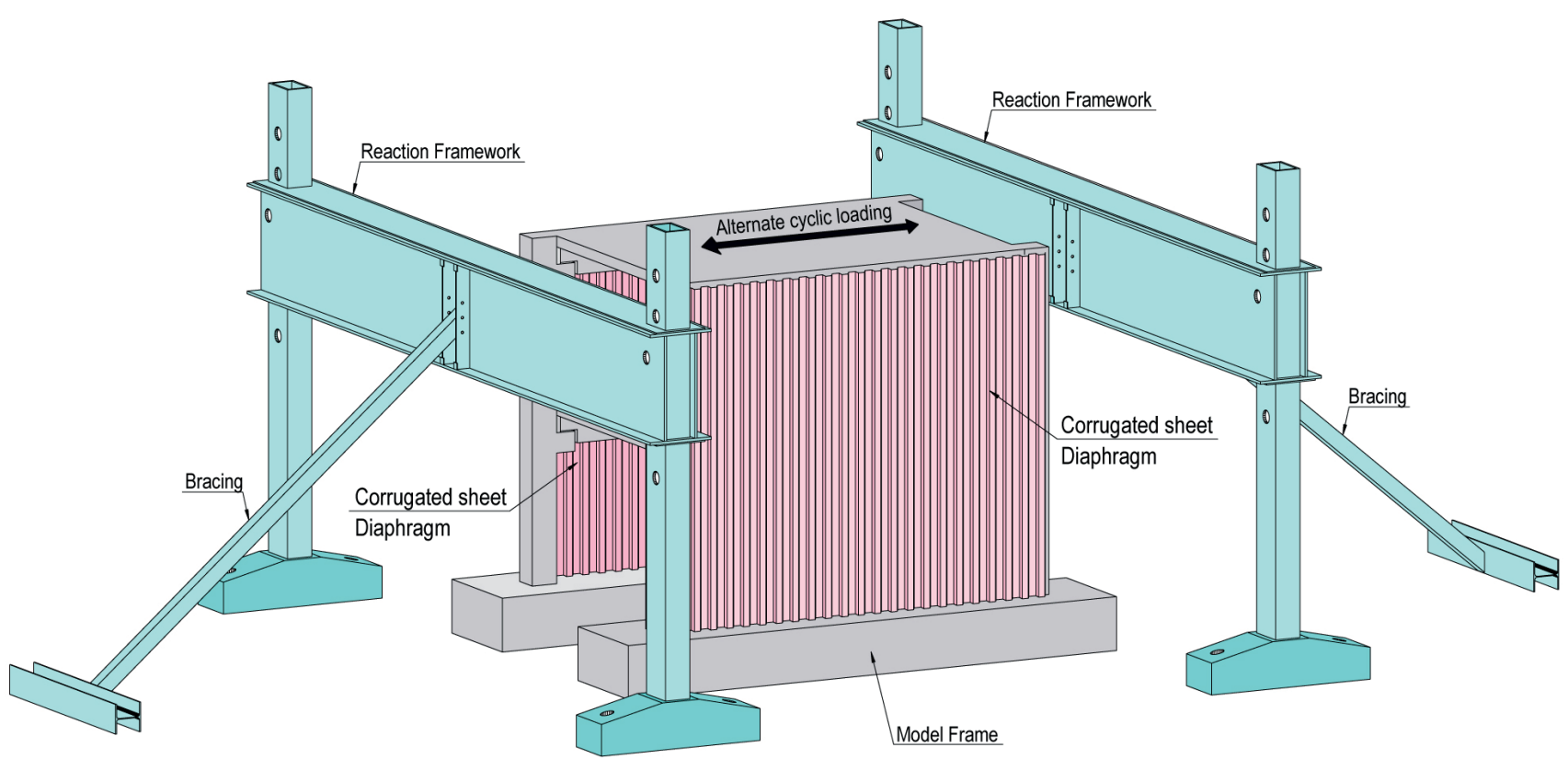

Fig. 4 Pad footings joint together to prevent slipping and uplifting [14] 
The columns support the precast beams through a corbel that has incorporated a steel dowel that secures the beam to the corbel.

The stirrup connectors in beams were designed to connect the precast part with the topping from the slabs. Longitudinal reinforcement bars are placed in the top corners of the stirrups for sagging moments. The longitudinal reinforcement is further anchored into the columns, using mechanical coupling catalogue elements. The concrete floor slabs were executed using cast in place concrete.

\section{Testing set-up and data acquisition}

The experimental test was conducted within the Laboratory of the Faculty of Construction of the Technical University of Cluj-Napoca.

The procedure followed in conducting the experiment is described in the American Standard ACI T1.1-01 "Acceptance Criteria for Moment Frames Based on Structural Testing". In order to be able to apply the cyclic loading steps described in the ACI T1.1-01 standard, a reaction framework was used. The reaction framework was laterally stiffened by means of abutments fixed in the floor with M100 bolts to prevent lateral displacements at the time of loading (Fig. 4). The placement of Model Frame was set to be put in the middle of the two reaction frameworks so that the loading could be applied alternatively from both ways [15].

This testing methodology indicates 11 loading steps that are to be accomplished. Each load step aims to achieve an imposed displacement at the top of the structure. This is also the ideology of the modern design codes that imposes drift restrictions at top of the building [16]. The target drifts are $0.20 \%, 0.25 \%, 0.35 \%, 0.50 \%, 0.75 \%, 1.00 \%, 1.40 \%$, $1.75 \%, 2.20 \%, 2.75 \%$ and $3.50 \%$ (ACI T1.1-01, [13]).

For each imposed displacement, three loading / unloading cycles were performed. Fig. 5 indicates the sequence of displacements carried out in the experiment.

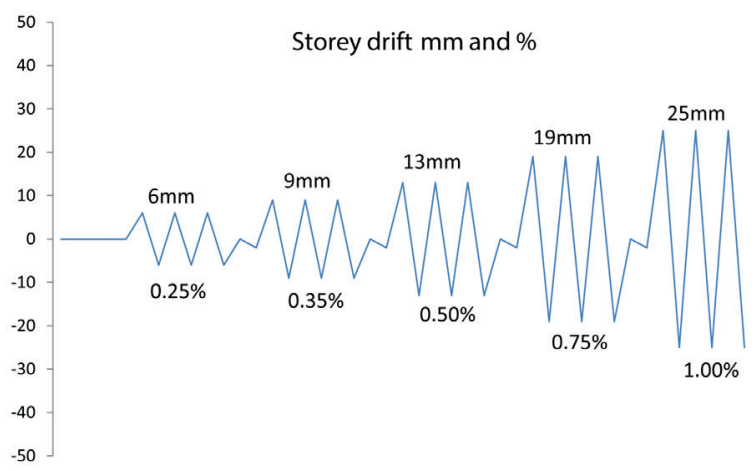

Fig. 5 Loading steps performed
On each side of the frame a diaphragm of 6 corrugated steel sheets was constructed (Fig. 6). By stiffening both sides of the frame, the torsion effect was prevented. The displacements at the top of the structure were recorded using an MGCplus data acquisition system connected to a desktop computer with CatmanEasy/AP 3.0 software developed by HBM Company. For measuring the necessary force for each imposed lateral displacement, two force pressure sensor of $1 \mathrm{MN}$ capacity were installed. The force in the structure was induced using a hydraulic jack (Fig. 7). The drift of the structure was measured using displacement sensors (HBM WA type of $100 \mathrm{~mm}$ and $300 \mathrm{~mm}$ ) and pressure sensors.

\section{Corrugated steel sheet set up}

In mounting the sheets to the reinforced concrete frame a fastening solution had to be adopted. The fasteners are of great importance because they are the constitutive elements that transfer the efforts from the structure to the sheet [17].

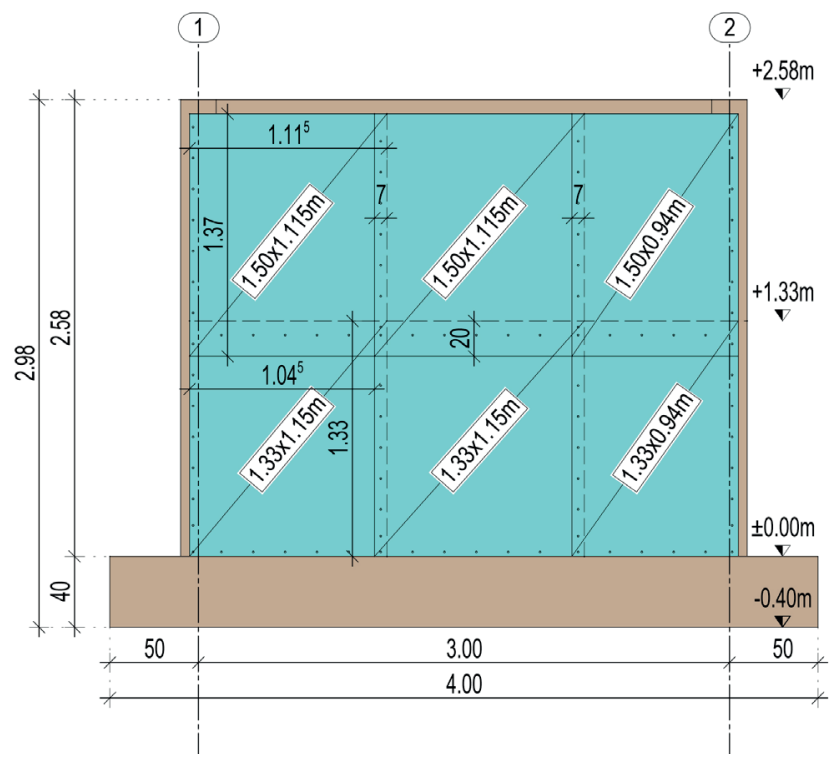

Fig. 6 Side view of the Model Frame with corrugated sheets attached

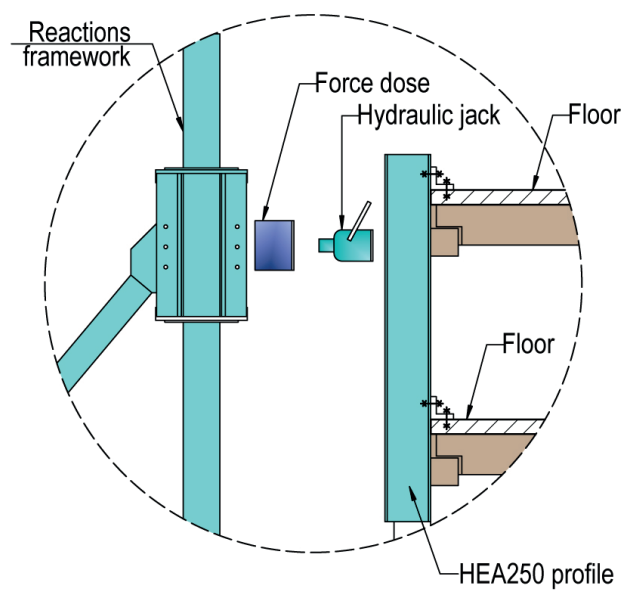

Fig. 7 Force application and measurement 
For reinforced concrete structures three possible solutions were identified that are most common for sheet fastening (Fig. 8). The Self-tapping screw and the nail plug both need prior drilling. The self-tapping screw is inserted using an electrical screwdriver and the nail plug is fixed in place using a hammer. The shooting steel nail uses dynamic force induced by a power machine.

The self-tapping BS-R $6.3 \mathrm{~L}=35 \mathrm{~mm}$ fastening solution from EJOT was adopted in fixating the sheet to the concrete frame (Fig. 9).

\subsection{Imperfect fastener to sheet contact}

Several obstacles came across during the attaching of the corrugated steel sheets to the concrete frame. The problems in fixing the corrugated sheets to the frame arise mainly from the fact that the reinforced concrete is a nonhomogenous material. The most common problem encountered in mounting the sheets to the frame was during the execution of the drilling in the concrete structure needed for the fastener.

Even if the position of the longitudinal reinforcement in an element is somehow easy to foresee and therefore it could be avoided, for stirrups the situation is different. Their exact place inside the concrete element is very difficult to identify, especially for beams and columns designed for seismic action that have dense stirrups at both ends mandatory for the development of the plastic hinge.
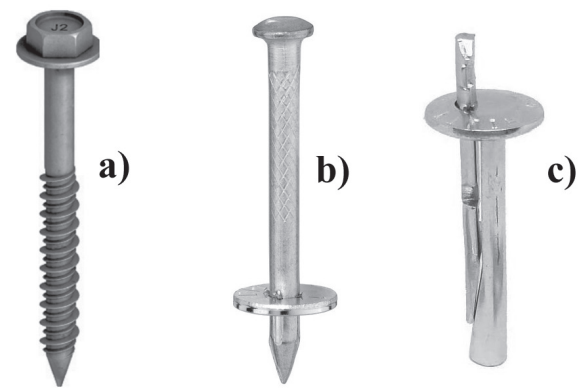

Fig. 8 Typical concrete fastening solution a) Self-Tapping Screw; b) Shooting steel nail; c) Nails Plugs
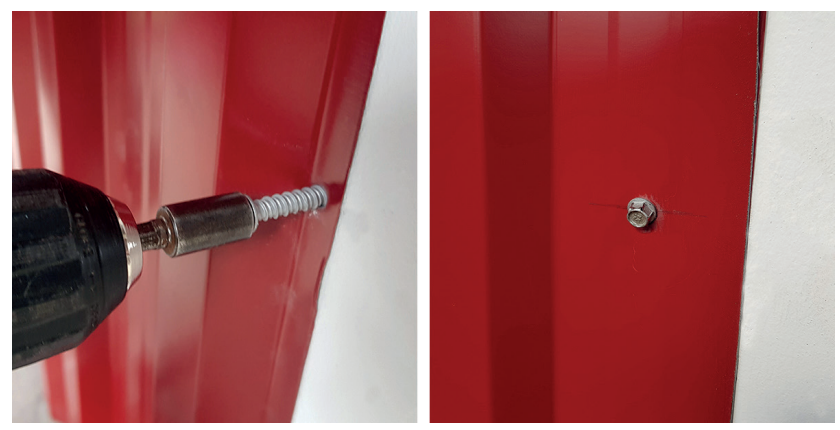

Fig. 9 Fastening the sheet on the Model Frame using BS-R screws
Moreover, after the concrete element is covered with the corrugated sheets, it becomes harder to identify the exact position of the reinforcement bars.

In many cases the head of the drill has intersected the reinforcement in the concrete element. The reinforcement blocked the drill bit to penetrate the necessary length for the fastener to proper fix the sheet. For this reason, reinforced concrete elements will frequently encounter situations when the drilling cannot fully go through. Each time such a situation was encountered, another drilling had to be done.

To solve this problem the first option was to try to penetrate again using the same point of entrance but from another angle. The purpose of drilling from the same point was to prevent additional damage in the sheet because it means a local weakening of the sheet. The process of executing the drills for the fastener it sometimes required to penetrate at a certain angle. Because of this the screw head had only partially contact with the sheet surface. If the contact surface between the head of the screw and the sheet is not perfect, the bearing capacity of the sheet diminishes substantially (Fig. 10).

\subsection{Sheet damage caused by repeated attempt to create a drill for fastening}

The corrugated sheets create the diaphragm effect only if they are proper fastened to the frame. In some cases the solution to try a different angle of penetration has succeeded. Often, however, even if a different route was tried at different angles, there was not always a way through. The only option was to try another penetration point implying the deterioration of the sheet (Fig. 11).

\section{Corrugated sheets acting as a diaphragm}

Although the process of fixing the corrugated sheets to the reinforced concrete frame bumped into problems due to the nature of the reinforced concrete bars, the operation succeeded in the end.

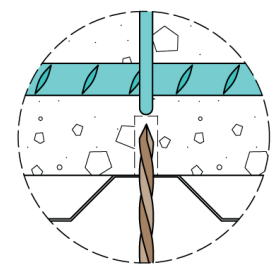

Step 1

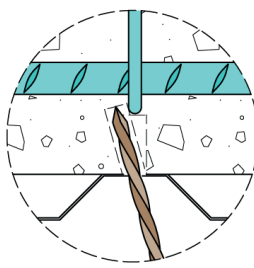

Step 2

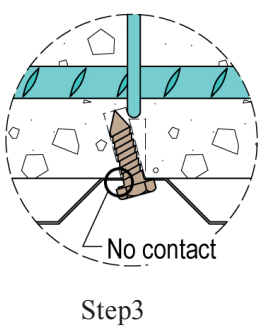

Step3
Fig. 10 Typical fastening imperfection

Step 1: Drill bit intersects reinforcement, Step 2: Drill bit penetration at angle to avoid reinforcement Step 3: Imperfect contact between fastener and sheet 


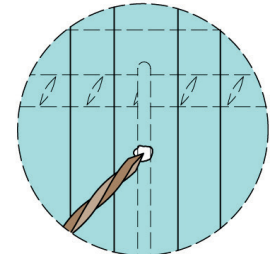

Step 1

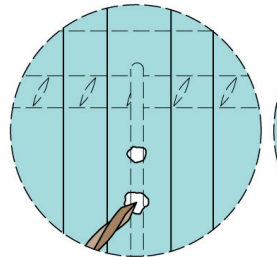

Step 2

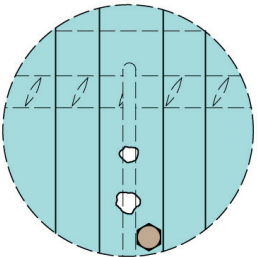

Step3
Fig. 11 Sheet damage due to repeated attempts to create drilling Step 1: Drill bit intersects reinforcement, Step 2: Drill bit intersects reinforcement again, Step 3: Fastening accomplished by damaging the sheet

With the sheets attached to the reinforced concrete frame, the intention was to compare its behavior with the corrugated steel sheets attached to a steel frame. The response of a sheet attached to a steel frame is well known and it can be summarized as becoming a bracing element that is tensioned diagonally (Fig. 12). The result of this effect is a concentrated effort directed to the fasteners in the corners.

The experimental test started following the ACI T1.1-01 indications. The first step was an imposed deflection of $6 \mathrm{~mm}$. The imposed deflection was obtained by applying a horizontal load $F_{b}=83.4 \mathrm{kN}$ in the positive direction (the positive direction is considered to be the direction in which the first loading step was applied). As expected, the corrugated sheets immediately started to deflect indicating that the fasteners were transmitting the efforts to the sheets (Fig. 13).

The next step was an imposed drift of $0.35 \%$. In this step a horizontal load $F_{b}=86.5 \mathrm{kN}$ was induced in the structure. The corresponding displacement was $\Delta=9.15 \mathrm{~mm}$. The visual inspection of the corrugated sheet panels revealed an incre-ase elongation of the holes around the fasteners (Fig. 14).

The experimental testing continued with the $0.50 \%$ drift step, consisting as for every step, in three loading and unloading cycles. The recorded relative displacement at the top of the structure was $\Delta=13,14 \mathrm{~mm}$ that corresponds to a horizontal displacement $F_{b}=100.98 \mathrm{kN}$. The distortion of the corrugated sheet panels propagated more and more through the diaphragm, leading to the failure of some of the fasteners in the top row (Fig. 15). With each loading step the deformation of the sheet affected a larger area. The observed behavior of the corrugated sheets so far is very much alike the behavior experienced by o sheet mounted on a steel frame.

In the next step, represented by the $0.75 \%$ drift, the relative top displacement obtained was $\Delta=19.20 \mathrm{~mm}$ with a corresponding horizontal loading $F_{b}=110.82 \mathrm{kN}$. After the three loading and unloading cycles were completed,

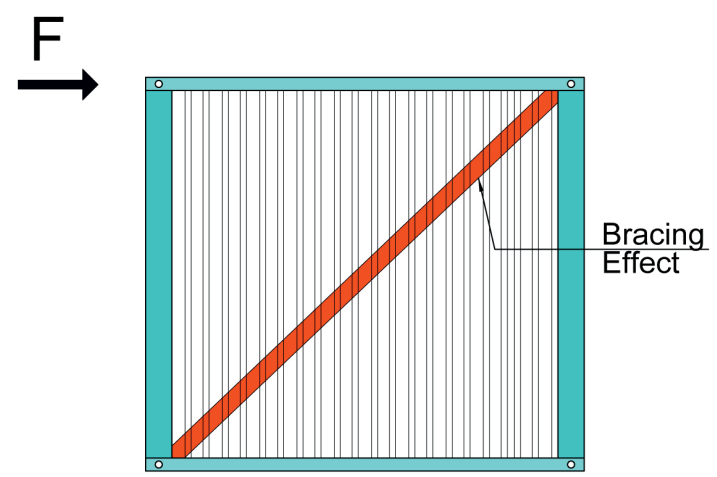

Fig. 12 Diaphragm acting as a bracing element

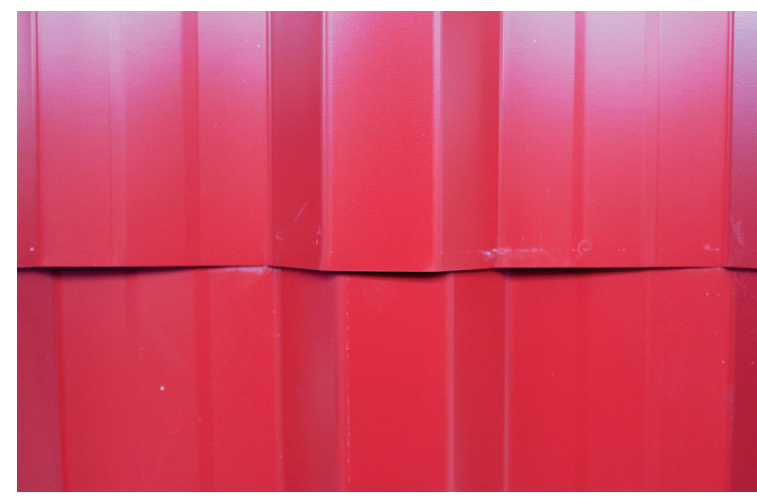

Fig. 13 Sheet distortion visible for first loading step $(0.25 \%$ drift $)$

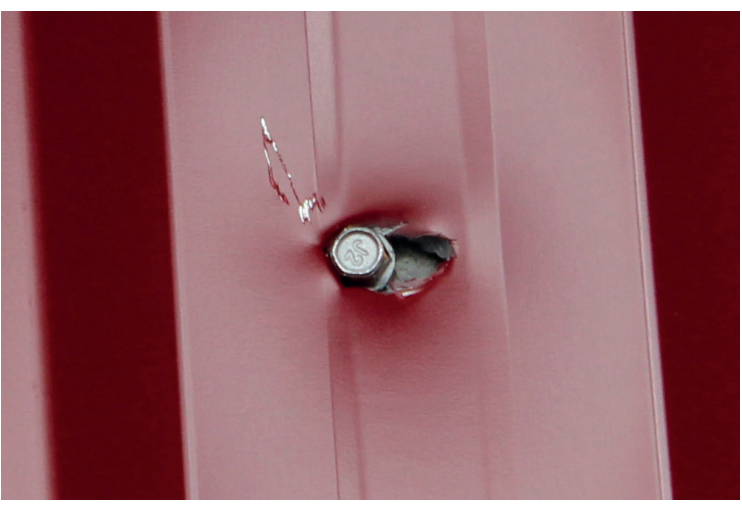

Fig. 14 Sheet distortion around fasteners $(0.35 \%$ drift $)$

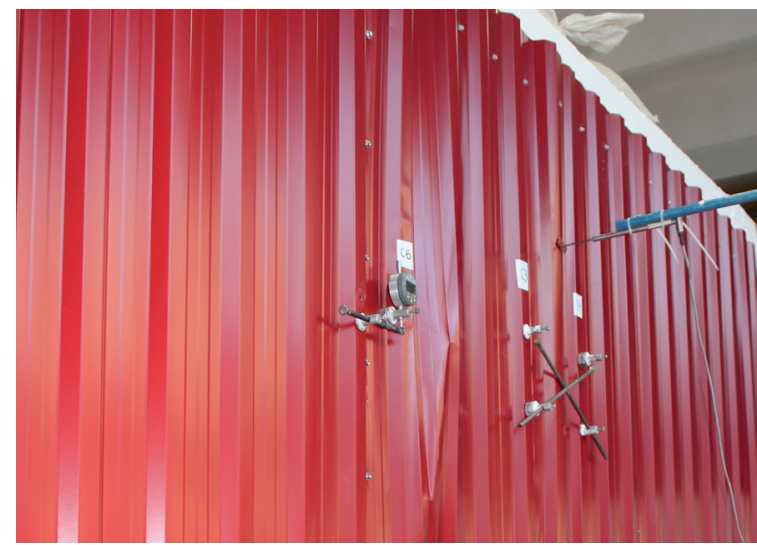

Fig. 15 Diaphragm distortion $(0.50 \%)$ 
it could be noted that the sheet distortion around fasteners increased, leading to contact failure between sheet and fasteners in the middle row.

The last step in the experimental testing was the $1.00 \%$ drift in which the top displacement was $\Delta=25.5 \mathrm{~mm}$ obtained by applying a horizontal load $F_{b}=117.66 \mathrm{kN}$ (Fig. 16).

With each step the warping of the diaphragm became more visible and the sheet started to cleft around the fasteners. The diaphragm strength degraded gradually during the loading and unloading steps determining over-deformations and excessive oval holes elongations around the fasteners fixed to the concrete frame.

In the last loading step, the corrugated sheets were not able to transmit stress to the concrete structure anymore because the fasteners could no longer create contact with the sheets. This meant that the corrugated panels were not active anymore. At this point the subsequent steps would be useless to be further investigated.

In Fig. 17 is plotted the envelope of the hysteresis loops obtained by performing the prescribed loading steps in the experimental testing conducted on the Model Frame.

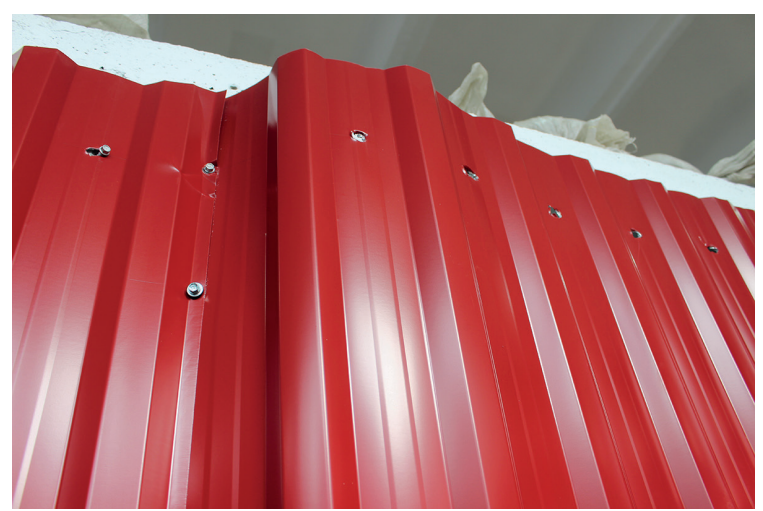

Fig. 16 Sheet distortion at the end of the experimental test (1.00\% drift)

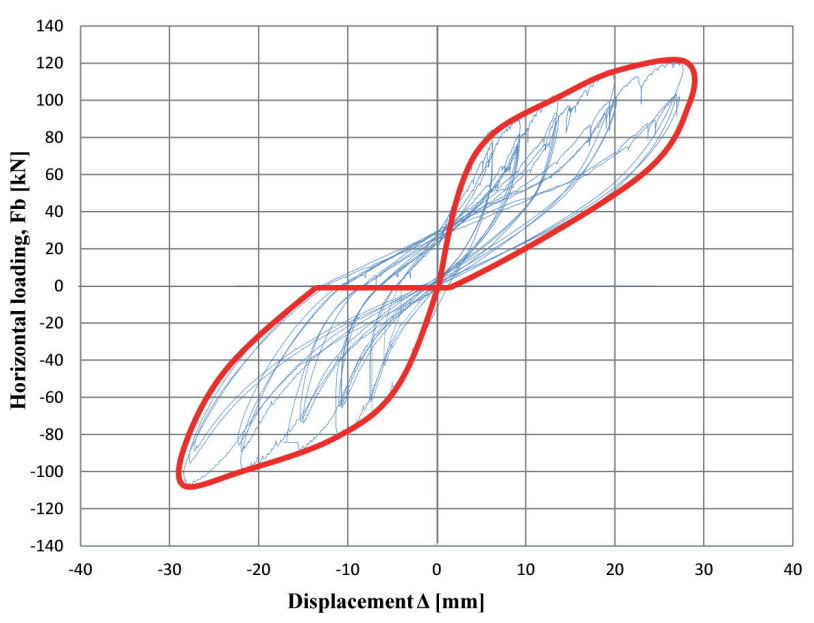

Fig. 17 Envelope of the hysteresis loops

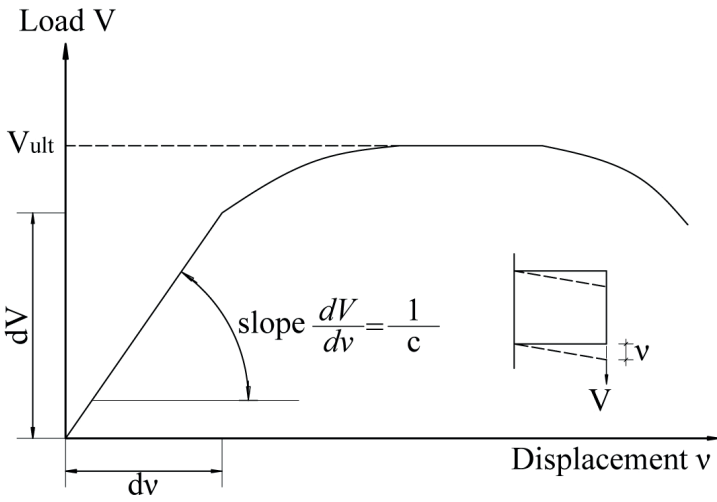

Fig. 18 Typical load-deflection curve of a shear panel [18]

From the force-displacement hysteresis curve it can be seen that the structural system behavior of the reinforced concrete frame is similar to the response obtained for steel frame structures described in the literature [1-9].

\section{Flexibility considerations in ECCS}

The European recommendations for sheeting acting as a diaphragm (ECCS), uses the term flexibility instead of stiffness. Flexibility is the reciprocal of stiffness. The diaphragm flexibility c is defined as the shear deflection per unit shear load in a direction parallel to the corrugation in the sheeting (Fig. 18).

For simple diaphragms, as in the case of our experimental test conducted on the Model Frame, the flexibility can be calculated by summing the partial flexibilities of the diaphragm. The partial flexibilities are considered to be:

Sheet distortion $c_{1.1}$

$c_{1.1}=\frac{a d^{2.5} \alpha_{1} \alpha_{4} K}{E t^{2.5} b^{2}}$

Sheet strain $c_{1.2}$

$c_{1.2}=\frac{2 a(1+\mu)(1+2 h / d)}{E \cdot t \cdot b}$

Sheet/Purlin fasteners $c_{2.1}$

$c_{2.1}=\frac{2 a \cdot s_{p} \cdot p}{b^{2}}$

Seam fasteners $c_{2.2}$

$c_{2.2}=\frac{2 s_{s} \cdot s_{p}\left(n_{s h}-1\right)}{2 n_{s} \cdot s_{p}+\beta_{1} \cdot n_{p} \cdot s_{s}}$

Sheet/Shear connector fasteners $c_{2.3}$

$c_{2.3}=\frac{2 s_{s c}}{n_{s c}}$ 
Axial strain $c_{3}$

$c_{3}=\frac{2 a^{3}}{3 E \cdot A \cdot b^{2}}$

Total shear flexibility

$c=c_{1.1}+c_{1.2}+c_{2.1}+c_{2.2}+c_{2.3}+c_{3}$

Where:

$c_{1.1}=$ flexibility due to distortion of the corrugation;

$c_{1.2}=$ flexibility due to the shear strain in the sheeting;

$c_{2.1}=$ flexibility due to movement in sheet to purlin fasteners;

$c_{2.2}=$ flexibility due to movement in seam fasteners;

$c_{2.3}=$ flexibility due to movement in shear connectors (in purlin to rafter connection in the case of direct shear transfer);

$c_{3}=$ flexibility due to the axial strain in the purlins (secondary framing members);

$a=$ the width of the corrugated sheet diaphragm in a direction perpendicular to the corrugations;

$A=$ the cross sectional area of a longitudinal edge member;

$b=$ the depth of the corrugated sheet diaphragm in the direction parallel to the corrugations;

$c=$ the total shear flexibility of a shear panel;

$d=\quad$ the pitch of the corrugations (Fig. 19);

$E=$ modulus of elasticity of steel;

$h=\quad$ the height of the sheeting profile (Fig. 19);

$K=$ sheeting constant which can take values $K_{1}$ or $K_{2}$ as given in Table 5.6 and Table 5.7 in ECCS [10];

$n_{p}=$ the number of purlin (edge + intermediate);

$n_{s}=$ the number of seam fasteners per slide lap (excluding those which pass through both sheets and the supporting purlin);

$n_{s c}=$ number of sheet to shear connector fasteners per end rafter;

$n_{s h}=$ number of sheet widths per shear panel;

$p=\quad$ the pitch of sheet/purlin fasteners;

$s_{p}=\quad$ is the slip per sheet/purlin fastener per unit load as given in Table 5.1 in ECCS

$s_{s c}=$ the slip per sheet/shear connector fastener per unit load as given in Table 5.1 in ECCS;

$s_{s}=\quad$ the slip per seam fastener per unit load as given in Table 5.1 in ECCS;

$t=\quad$ the net sheet thickness (Fig. 19);

$\alpha_{1}$ and $\alpha_{4}=$ are the factors to allow for intermediate purlins and number of sheet lengths as given in Table 5.4 and Table 5.8 in ECCS; $\mu=\quad$ Poisson's ratio (for steel 0.3);

$\beta_{1}=$ factor to allow for the number of sheet/purlin fasteners per sheet width as given in Table 5.2 in ECCS.

From Eqs. (1) to (7) it can be observed that ECCS considers three main flexibility factors for the diaphragm: the sheet, the fasteners and the axial strain flexibility.

The experimental test conducted on the Model Frame showed that the main difference in reinforced concrete structures is given by the sheet to purlin fasteners $\left(c_{2.2}\right)$. The reason is that the nature of the concrete creates an uncertain fastening of the sheet. For steel structures that is not the case. There is no difficulty in creating perfect fastening each time.

Comparing the behavior of the corrugated steel sheets attached to the reinforced concrete frame with the behavior of the sheets attached to a steel frame is can be seen that there are no significant differences between the two. The corrugated steel sheets behave in the same way regardless if it is attached to a steel frame or to a reinforced concrete frame.

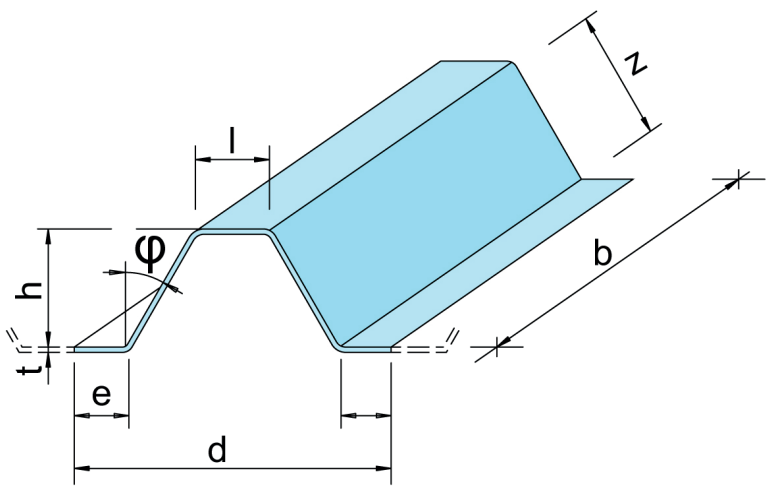

Fig. 19 Geometry of a single corrugation

Table 3 Similarities of shear flexibility components between steel and reinforced concrete frame

\begin{tabular}{|c|c|c|}
\hline $\begin{array}{l}\text { Components of shear flexibility } \\
\text { expressed in ECCS compared } \\
\text { to concrete frame }\end{array}$ & \multicolumn{2}{|c|}{$\begin{array}{c}\text { Assumed Similarities with RC } \\
\text { frame }\end{array}$} \\
\hline $\begin{array}{c}\text { Profile } \\
\text { distortion } c\end{array}$ & \multicolumn{2}{|c|}{ Identical } \\
\hline Shear strain $c_{1.2}$ & \multicolumn{2}{|c|}{ Identical } \\
\hline \multirow{3}{*}{$\begin{array}{c}\text { Fastener } \\
\text { Deformation }\end{array}$} & $\begin{array}{l}\text { Sheet to purlin } \\
\text { fastener } c_{2.1}\end{array}$ & Not Identical \\
\hline & $\begin{array}{c}\text { Seam fasteners } \\
c_{2.2}\end{array}$ & Identical \\
\hline & $\begin{array}{l}\text { Connections to } \\
\text { rafters } c_{2.3}\end{array}$ & $\begin{array}{l}\text { No existent } \\
\text { in reinforced } \\
\text { concrete frames }\end{array}$ \\
\hline Flange forces & $\begin{array}{l}\text { Axial strain in } \\
\text { purlins } c_{3}\end{array}$ & Not Identical \\
\hline
\end{tabular}


The experimental test conducted on the Model Frame presented the particularities encountered during the fixing of the corrugated sheet on the reinforced concrete frame.

Based on the particularities observed in the study, in Table 3 are presented the differences that should be taken into account when calculating the flexibility of a diaphragm acting on a reinforced concrete frame using the ECCS equations.

\section{Conclusions}

The article presents the experimental test performed on a reinforced concrete frame laterally stiffened with corrugated steel sheets. The study was conducted using the

\section{References}

[1] Davies, J. M. "Developments in stressed skin design", Thin-Walled Structures, 44(12), pp. 1250-1260, 2006. https://doi.org/10.1016/j.tws.2007.01.002

[2] Davies, J. M. "A general solution for the shear flexibility of profiled sheets. I: Development and verification of the method", Thin-Walled Structures, 4(1), pp. 41-68, 2006.

https://doi.org/10.1016/0263-8231(86)90009-1

[3] Lendvai, A., Joó, A. L., Dunai, L. "Experimental full-scale tests on steel portal frames for development of diaphragm action - Part I experimental results", Thin-Walled Structures, 132, pp. 729-739, 2018.

https://doi.org/10.1016/j.tws.2018.06.001

[4] Lendvai, A., Joó, A. L. "Experimental full-scale tests on steel portal frames for development of diaphragm action - Part II Effect of structural components on shear flexibility", Thin-Walled Structures, 132, pp. 740-758, 2018.

https://doi.org/10.1016/j.tws.2018.06.006

[5] Avci, O., Luttrell, L. D., Mattingly, J., Easterling, W. S. "Diaphragm shear strength and stiffness of aluminum roof panel assemblies", Thin-Walled Structures, 106, pp. 51-60, 2016.

https://doi.org/10.1016/j.tws.2016.04.019

[6] Massarelli, R., Franquet, J.-E., Shrestha, K., Tremblay, R., Rogers, C. A. "Seismic testing and retrofit of steel deck roof diaphragms for building structures", Thin-Walled Structures, 61, pp. 239-247, 2012. https://doi.org/10.1016/j.tws.2012.05.013

[7] Baehre, R. "The stressed skin design of steel structures: (ECCS Publication No. 19(1978)", Thin-Walled Structures, 4(1), pp. 79, 1986. https://doi.org/10.1016/0263-8231(86)90011-X

[8] Sputo, T. "Steel Roof Deck Diaphragms on Cold-Formed Steel Framing", In: 20th International Specialty Conference on ColdFormed Steel Structures, St. Louis, MI, USA, 2010, pp. 283-296. [online] Available at: https://scholarsmine.mst.edu/isccss/20iccfss/ 20iccfss-session6/3/

[9] SDI "Diaphragm Design Manual 4th Edition - No. DDM04", Steel Deck Institute, Pittsburgh, PA, USA, 2015.

[10] ECCS "European Recommendations for the application of metal sheeting acting as a diaphragm", European Convention for Constructional Steelwork, No. 88, Brussels, Belgium, 1995. testing methodology presented in the ACI T1.1-01. At the moment there are neither guides nor recommendations on how to include the diaphragm effect of the sheeting on reinforced concrete frames. The article prepared the first steps for future research by identifying the main discrepancies between reinforced concrete structures and steel structures and concluded that they are mainly due to sheet to purlin fastening.

The study also presents the problems encountered during the execution of the fixing of the corrugated sheets to the concrete frame and offers solutions. The investigation showed that the sheet response to shear loading is similar to the one obtained in steel structures.

[11] Mohsen, G., Mohsen, L., Roya, N. "Inelastic behavior of cold-formed braced walls under monotonic and cyclic loading", International Journal of Advanced Structural Engineering, 7, pp. 181-209, 2015. https://doi.org/10.1007/s40091-015-0091-8

[12] Zhang, W., Wang, J., Mahdavian, M., Yu, C. "Seismic Performance of Cold-Formed Steel Framed Buildings Using Corrugated Sheet Shear Walls", presented at Geotechnical and Structural Engineering Congress 2016, Phoenix, AZ, USA, Feb, 14-17, 2016. https://doi.org/10.1061/9780784479742.021

[13] ACI Committee 93 "T1.1-01/T1.1R-01: Acceptance Criteria for Moment Frames Based on Structural Testing", American Concrete Institute, Farmington Hills, MI, USA, 2001.

[14] Toader, N. "Multistory precast reinforced concrete structures with semirigid connections", PhD Thesis, Technical University of ClujNapoca, 2015.

[15] Țere, S.-G., Hegheş, B., Constantinescu, H., Toader, T.-N. "Study on the Rigidity of a Precast Concrete Frame with and Without Rigidization with Corrugated Sheets", Bulletin of the Polytechnic Institute of Jassy, Construction, 65(69), pp. 35-42, 2019. [online] Available at: http://www.bipcons.ce.tuiasi.ro/Content/ ArticleInformation.php?ArticleID=706

[16] BSI "BS EN 1998-1:2004 Eurocode 8: Design of structures for earthquake resistance - Part 1: General rules, seismic actions and rules for buildings", British Standard, London, UK, 2004.

[17] Simaan, A., Winter, G., Pekoz, T. "Fastener strength in diaphragm braced members", Department of Structural Engineering School of Civil and Environmental Engineering Cornell University, Ithaca, NY, USA, Rep. 341, 1971. [online] Available at: https://scholarsmine. mst.edu/cgi/viewcontent.cgi?article=1019\&context=ccfss-library

[18] Davies, J. M. "Chapter 7: Residential buildings", In: Rondal, J., Dubina, D. (eds.) Light Gauge Metal Structures Recent Advances, Springer-Verlag, Wien, Austria, 2005, pp. 143-188. https://doi.org/10.1007/3-211-38023-X 